\title{
Relative priming of temporal local-global levels in auditory hierarchical stimuli
}

\author{
Alexandra List \\ University of California, Berkeley, California \\ Medical Research Service, Department of Veterans Affairs Medical Center, Martinez, California \\ and University of Wales, Bangor, Wales \\ AND \\ Timothy Justus \\ University of California, Berkeley, California \\ and Medical Research Service, Department of Veterans Affairs Medical Center, Martinez, California
}

\begin{abstract}
Priming is a useful tool for ascertaining the circumstances under which previous experiences influence behavior. Previously, using hierarchical stimuli, we demonstrated (Justus \& List, 2005) that selectively attending to one temporal scale of an auditory stimulus improved subsequent attention to a repeated (vs. changed) temporal scale; that is, we demonstrated intertrial auditory temporal level priming. Here, we have extended those results to address whether level priming relied on absolute or relative temporal information. Both relative and absolute temporal information are important in auditory perception: Speech and music can be recognized over various temporal scales but become uninterpretable to a listener when presented too quickly or slowly. We first confirmed that temporal level priming generalized over new temporal scales. Second, in the context of multiple temporal scales, we found that temporal level priming operates predominantly on the basis of relative, rather than absolute, temporal information. These findings are discussed in the context of expectancies and relational invariance in audition.
\end{abstract}

Prior experiences can influence present behavior in many ways. Here, we focus on priming - that is, changes in behavior based on repeated relative to novel experiences. Frequently, the repetition of an experience leads to improvements in behavior, although in certain cases, repetition can impair behavior (e.g., negative priming; Tipper, 1985). Priming between the initial and repeated experience may be observed across a broad range of temporal delays: on the order of seconds (e.g., on a trial-bytrial basis), hours, days, or months (e.g., within or across testing sessions). Note that any change in behavior related to the repetition or novelty of a situation indicates an influence of previous events. For this reason, priming is a powerful experimental tool for understanding what experiences or aspects of those experiences are important in determining behavior over time.

In the present study, we examined how the current processing of an auditory stimulus is influenced by the processing of the immediately preceding auditory stimulus (i.e., auditory priming). To situate the present study, we first describe some of the rich literature on how preceding experiences influence current auditory processing. The most straightforward example of prior influence on current processing is repetition, or sensory, priming: When perceivers are presented with one stimulus, performance is enhanced for the same ensuing stimulus. One illustrative example from audition comes from Ward (1997), who showed that presenting two tones in succession of the same (vs. different) frequency improved performance on an orthogonal intensity judgment task (see also, e.g., the uninformative cue conditions in Green \& McKeown, 2001).

There are also more sophisticated forms of auditory priming beyond those found with stimulus repetition. For example, Bharucha and Stoeckig (1986) demonstrated priming between two harmonically related vs. unrelated chords: Performance was better for harmonically related chords. This priming advantage was not reliant on repetition priming, as was demonstrated by its persistence even when any overlap in frequency spectra was removed from the chord pairs (Bharucha \& Stoeckig, 1987). Tekman and Bharucha (1998) demonstrated a compelling extension of this finding: Priming was stronger between chords with a close harmonic relation, even when the more distant harmonic relation contained greater overlap in frequency spectra. The last example reveals that repetition priming can be overcome by other forms of priming.

Bigand and colleagues further elaborated on the priming paradigm by demonstrating harmonic priming using a temporally extended frequency context; that is, within

A. List, a-list@northwestern.edu 
a trial, several events set up a tonal context that affected the processing of the final event (e.g., Bigand \& Pineau, 1997; Bigand, Poulin, Tillmann, Madurell, \& D'Adamo, 2003; Johnston \& Jones, 2006; Marmel, Tillmann, \& Dowling, 2008; Tillmann, Bigand, \& Pineau, 1998; Tillmann \& Lebrun-Guillaud, 2006). Namely, judgments of, for example, completion, timbre, or mistuning were improved if the final event was harmonically related to the preceding context relative to when it was not. Together, these examples of priming effects illustrate that lifelong experiences with tonal schemata induce listeners to create expectations for temporally proximal auditory events to be harmonically related.

The creation of expectations by a temporally extended context need not rely on tonal schemata, however. Other demonstrations exist using, for example, good continuation of pitch (i.e., each successive tone is higher or lower). For example, Johnston and Jones (2006, Experiment 1) presented listeners with a series of isochronous tones either continually rising or falling in pitch. The listeners judged final tones to be deviating toward the implied pitch trajectory, indicating that a biasing expectation was created from the ascending or descending pitch context. The combined frequency and temporal regularities thereby altered ensuing auditory processing, suggesting that experience with immediate, as well as lifelong, regularities (described above) produce expectations in the perceiver (see also Crum \& Hafter, 2008, for another approach).

Temporal regularities alone have also been shown to produce expectations in listeners. A number of studies have shown that frequency-based judgments were improved for temporally expected events (e.g., Boltz, 1998; Dowling, Bartlett, Halpern, \& Andrews, 2008; Dowling, Lung, \& Herrbold, 1987; Jones, Johnston, \& Puente, 2006; Jones, Moynihan, MacKenzie, \& Puente, 2002; Kidd, Boltz, \& Jones, 1984; Schmuckler \& Boltz, 1994; Tillmann \& Lebrun-Guillaud, 2006). For example, Dowling et al. (1987, Experiment 6) showed that participants were better able to discriminate melodies when the critical tones were presented on (vs. off) the beat. Complementary research from Tillmann and Lebrun-Guillaud (2006) showed that participants were better able to make timbre judgments when chords were presented at an expected point in time. Jones et al. (2002) demonstrated that pitch judgments were improved when tones were rhythmically expected versus unexpected. In addition, other investigations have revealed that temporal regularities influenced the perceived temporal characteristics of an event (e.g., Barnes \& Jones, 2000; Deutsch, 1986; Drake \& Botte, 1993; Jones \& Boltz, 1989; Jones \& McAuley, 2005; Large \& Jones, 1999; McAuley \& Miller, 2007; Repp, 2002; Yee, Holleran, \& Jones, 1994). Large and Jones required listeners to detect time changes in regular versus irregular temporal contexts and found that listeners' performance was better after exposure to regular contexts. Taking another approach, McAuley and Miller asked participants to perform temporal interval comparisons in one of two tempo contexts: The session tempo mean was either fast or slow. They found that the participants' temporal judgment errors deviated toward the session mean, indicating that the temporal context exerted an influence over temporal interval estimation. Together, these results, along with other converging evidence, indicate that temporal regularities in the environment can induce both frequency and temporal expectancies in the listener.

In the present study, we examined yet another form of past influence on current auditory processing. Here, we examined how attending to one aspect of a stimulus influences attention to subsequent stimuli. Although a subtle issue, it is important to differentiate the perception of an event from selectively attending to only one part or one aspect of an event. In some of the research described above, the investigations were focused on how perception was influenced by prior experience. However, in the present study, we examined how selectively attending to a certain temporal scale within a stimulus is influenced by the prior scale of attention. Our interest is also subtly but critically different from an environmental entrainment of attention, as in dynamic attending theory, proposed by Jones and colleagues (e.g., Drake, Jones, \& Baruch, 2000; Jones, 1976; Jones \& Boltz, 1989; Large \& Jones, 1999). Dynamic attending theory posits that attention becomes synchronized (in phase and period) with temporal regularities in the environment. This periodic attending results in expectancies for future events at particular points in time. We hypothesized that, just as the environment (e.g., rhythm, tempo) might entrain a listener's attention and thereby create expectations at particular points in time, selecting a relevant scale of auditory information would induce a listener to select the same scale of auditory information during a subsequent event. In order to test this hypothesis, we used a task and stimuli that required listeners to selectively attend to certain aspects of the auditory information presented to them and we measured how this selection influenced subsequent selection.

Specifically, we previously developed an empirical approach to address how, in the presence of multiple temporal scales, listeners' selection of one auditory temporal scale influenced their subsequent selection of auditory information (Justus \& List, 2005). We used experimental designs based on well-known visual studies that employed stimuli whose information was hierarchically structured. In the same way that a visual local pattern is repeated over space to produce a global pattern (Figure 1A; Navon, 1977), we designed auditory stimuli in which a local pattern was repeated over time to produce a global pattern (Figure 1B). Using these stimuli, we demonstrated that identifying an auditory pattern at one level of a hierarchical stimulus in one trial facilitates the identification of a pattern if it appears at the same hierarchical level in the following trial (e.g., Justus \& List, 2005, Experiment 2), as has been reported with hierarchical levels in vision (Robertson, 1996; Ward, 1982). Specifically, local pattern identification is faster when preceded by local pattern identification (vs. global pattern identification), and global pattern identification is faster when preceded by global pattern identifi- 


\section{A Visual Hierarchical Stimuli}

\begin{tabular}{|c|c|c|c|c|c|}
\hline & & & Local Pattern & & \\
\hline & $\mathrm{H}$ & $S$ & & A & $E$ \\
\hline 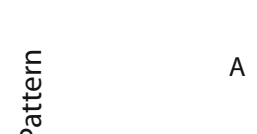 & $\begin{array}{lr}\mathrm{H} H H H \\
\mathrm{H} & \mathrm{H} \\
\mathrm{H} H H H \\
\mathrm{H} & \mathrm{H} \\
\mathrm{H} & \mathrm{H}\end{array}$ & $\begin{array}{l}\text { SSSS } \\
\text { S } \\
\text { SSSS } \\
\text { SS S } \\
\text { S } \\
\text { S } \\
\text { S }\end{array}$ & $\mathrm{H}$ & $\begin{array}{lr}A & A \\
A & A \\
A & A A A \\
A & A \\
A & A\end{array}$ & $\begin{array}{ll}\mathrm{E} & \mathrm{E} \\
\mathrm{E} & \mathrm{E} \\
\mathrm{E} & \mathrm{E} \\
\mathrm{E} & \mathrm{E} \\
\mathrm{E} & \mathrm{E}\end{array}$ \\
\hline 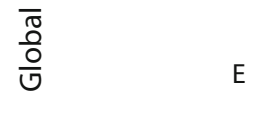 & $\begin{array}{l}\mathrm{HHHH} \\
\mathrm{H} \\
\mathrm{H} H \mathrm{H} \\
\mathrm{H} \\
\mathrm{H} H \mathrm{H}\end{array}$ & $\begin{array}{l}\text { SSSS } \\
\text { S } \\
\text { SSSS } \\
\text { S } \\
\text { SSSS }\end{array}$ & $S$ & $\begin{array}{l}\text { AAAA } \\
\text { A } \\
\text { AAAA } \\
\text { A } \\
\text { AAAA }\end{array}$ & $\begin{array}{l}\mathrm{EEEE} \\
\mathrm{E} \\
\mathrm{EEEE} \\
\mathrm{E} \\
\mathrm{EEE}\end{array}$ \\
\hline
\end{tabular}

B

Auditory Hierarchical Stimuli

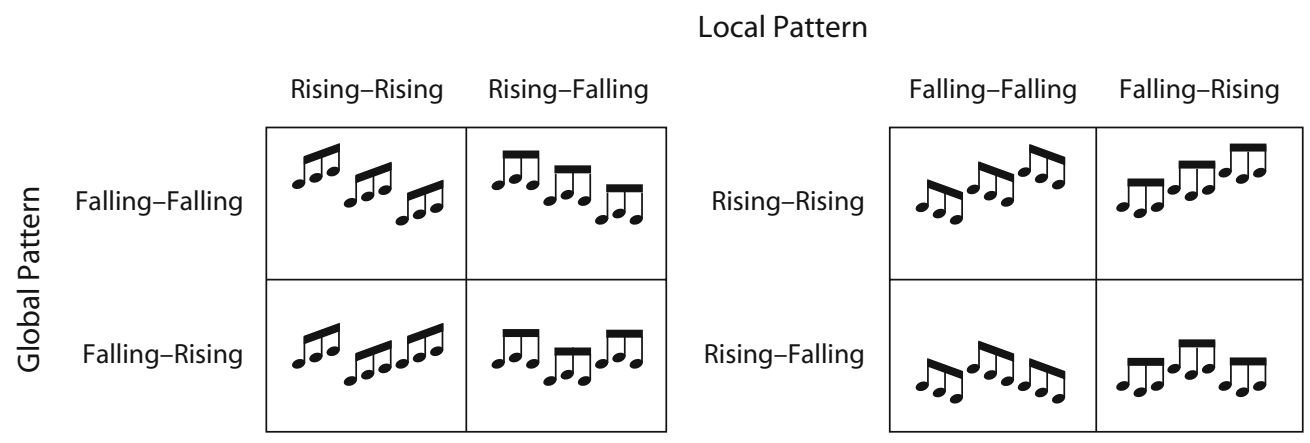

Figure 1. Visual (A) and auditory (B) hierarchical stimuli in which a local pattern is repeated to form a global pattern. In panel $A$, the patterns $H$ and $S$ are crossed with patterns $A$ and $E$. In panel $B$, the risingrising and rising-falling patterns are crossed with the falling-falling and falling-rising patterns.

cation (vs. local pattern identification). This is true even if the specific pattern changes and is therefore not the product of stimulus repetition. This type of priming has been termed level priming. To our knowledge, ours was the first study to demonstrate auditory level priming: Attending to a pattern presented over one temporal scale facilitates attending to subsequent patterns presented over the same temporal scale, even when the pattern changes.

Our studies differ in two important ways from others in which selective attention to auditory temporal information was required. First, in our studies, participants did not make explicit temporal judgments (e.g., duration estimates); instead, they identified melodic patterns regardless of temporal scale. Here, the temporal manipulation is orthogonal to their task. Second, because every hierarchical stimulus contains two scales of information (local and global), the participants must selectively attend to one of the two available scales to successfully perform their task.

The terms local and global have been used to describe many different properties in auditory research. For instance, Peretz and others (e.g., Peretz, 1990; Schiavetto, Cortese, \& Alain, 1999) have used the term local to describe pitch intervals and global to describe pitch contours. Others have described temporal intervals within a trial as local occurring within a broader global tempo context, as was described above (e.g., Jones \& McAuley,
2005; McAuley \& Miller, 2007). In studies of harmonic priming, Bigand and Pineau (1997) and Tillmann et al. (1998) described the influence of an immediately preceding chord as local, and the influence of the preceding sequence of chords as global (for still other uses, see, e.g., Dyson \& Alain, 2008; Horváth, Czigler, Sussman, \& Winkler, 2001). Because the terms have been used in such a varied manner, we emphasize our usage here, which differs from those described above. In our study, local and global refer to two levels of one hierarchical stimulus in one trial.

In the present experiments, we extended our previous findings in which only two temporal scales were probed: 300 and $900 \mathrm{msec}$. First, we address whether the level-priming results generalize to temporal scales other than those that have been tested. Second, we address whether level priming is due to the selection of absolute or relative temporal scales. Because stimuli were only presented over fixed scales-local and global absolute dimensions did not change-it is undetermined whether level priming was mediated by the priming of absolute or relative temporal scales. In other words, was an absolute temporal scale (e.g., 300 or $900 \mathrm{msec}$ ) primed? Or, was the relative hierarchical level (i.e., local or global) primed?

The distinction between absolute and relative temporal information is an important one in auditory perception. For 
instance, listeners are able to recognize melodies played at a variety of different tempi, or temporal presentation rates, indicating their ability to disregard absolute temporal information when necessary (e.g., Andrews, Dowling, Bartlett, \& Halpern, 1998; Warren, Gardner, Brubaker, \& Bashford, 1991). However, these studies have also revealed absolute temporal limits to this ability. The lower boundaries were estimated to be on the order of hundreds of milliseconds between tones, and the upper boundaries were estimated to be on the order of seconds between tones (see also Fraisse, 1946, 1963, 1982). Taking another approach, Halpern (1988) asked listeners to imagine melodies and to report the imagined tempo, as well as the fastest and slowest tempi imaginable for the melodies. The participants were able to imagine melodies over varied tempi, revealing relative temporal capabilities, but, again, there were limits, revealing some absolute temporal constraints. These previous studies, as well as the present work, were focused on the invariance of melodic pitch patterns across temporal transformations, as opposed to the invariance of rhythmic patterns across temporal transformations (Handel, 1993; Lewkowicz \& Marcovitch, 2006).

In Experiment 1, we aimed to replicate intertrial temporal level priming and to extend it to other (longer) absolute temporal scales. Rather than using a stimulus set in which local and global patterns unfolded over 300 and $900 \mathrm{msec}$, respectively, referred to hereinafter as the fast-intermediate (FI) stimulus set (Justus \& List, 2005; List \& Justus, 2007; List, Justus, Robertson, \& Bentin, 2007), we instead used a new stimulus set in which local and global patterns unfolded over 900 and 2,700 msec, respectively, referred to hereinafter as the intermediate-slow (IS) stimulus set. Experiment 1 was a necessary precedent for Experiment 2, in which we interleaved the two stimulus sets.

In Experiment 2, we aimed to determine whether intertrial temporal level priming operates on the basis of absolute or relative temporal information. By interleaving the IS and FI stimulus sets, we were able to measure temporal level priming in two informative conditions: when the stimulus set repeated between successive trials and when the stimulus set changed between successive trials. When the stimulus set changed, we could determine whether temporal level priming extended across stimulus sets to reveal relative or absolute temporal influences from one trial to the next. When the stimulus set repeated, we could determine whether temporal level priming persisted within each stimulus set in the context of interleaved stimulus sets.

\section{EXPERIMENT 1}

In Experiment 1, we repeated Experiment 2 from Justus and List (2005), using stimuli unfolding over longer temporal scales than were originally used. Previously, the local and global temporal scales spanned 300 and 900 msec (the FI stimulus set), whereas in this experiment the local and global temporal scales unfolded over 900 and 2,700 msec (the IS stimulus set), respectively. If our previous findings relied on the precise temporal parameters of our stimuli (i.e., showed stimulus specificity), level priming should not extend to other temporal scales.
If our previous findings captured a more general property of auditory temporal processing, level priming should extend to other temporal scales.

\section{Method}

\section{Participants}

Sixteen individuals from the Bangor, Wales, community were recruited. For their participation, 8 participants were financially compensated, and 8 participants received course credit. Fourteen reported right-handedness and two reported left-handedness. All reported normal hearing and at least some musical experience (median $=10$ years, range $=2-20$ years). Their median age was 20 years (range $=18-33$ years)

\section{Stimuli}

Nine complex tones were created with fundamental frequencies ranging from 185 to $467 \mathrm{~Hz}\left(\mathrm{~F}_{3}-\mathrm{A} \sharp_{4}\right)$, each lasting $300 \mathrm{msec}$. Each tone consisted of the fundamental frequency and the next four harmonics (at $1 / n$ amplitude), and ramped on and off over $10 \mathrm{msec}$. The tones corresponded to musical notes, each one whole step away from its neighbors.

The tones were sequentially grouped into triplets (i.e., three-tone sequences) without interstimulus intervals (ISIs), creating four local patterns that differed in pitch contour: rising-rising, rising-falling, falling-rising, and falling-falling (Figure 1B), where rising denotes a transition from a lower to a higher frequency tone and falling denotes the opposite. We use the term local pattern to describe the pitch contour formed by these three adjacent tones, without regard to their absolute frequencies. For example, a falling-rising local pattern could be presented in a low, mid, or high pitch range: $\left[A \sharp_{3}-G \sharp_{3}-A \sharp_{3}\right.$ ], $\left[\mathrm{E}_{4}-\mathrm{D}_{4}-\mathrm{E}_{4}\right]$, or $\left[\mathrm{A}_{4}-\mathrm{G}_{4}-\mathrm{A}_{4}\right]$, respectively.

Global patterns were created by presenting three instances of one local pattern sequentially without ISIs over three possible pitch ranges, resulting in a nine-tone hierarchical stimulus. As with the term local pattern, the term global pattern describes the pitch contour formed by three elements: here, the adjacent local patterns. Global patterns were similarly rising-rising, rising-falling, falling-rising, or falling-falling (Figure 1B). For example, a local falling-rising pattern forming a global rising-rising pattern would be $\left[\mathbb{A}_{3}-\mathrm{G}_{3}-\mathrm{A}_{3}\right]-\left[\mathrm{E}_{4}-\mathrm{D}_{4}-\mathrm{E}_{4}\right]-\left[\mathrm{A}_{4}-\mathrm{G}_{4}-\mathrm{A}_{4}\right]$, as is shown in the top right corner of Figure 1B.

Figure 1B illustrates the full stimulus set used in this experiment. In creating the eight stimuli, only two patterns (rising-rising and rising-falling) were crossed with two other patterns (falling-falling and falling-rising). Note that the pattern combinations were never redundant across levels (e.g., a falling-falling local pattern was never combined with a falling-falling global pattern).

Within each hierarchical stimulus in the IS stimulus set, each local pattern spanned $900 \mathrm{msec}$ and the global pattern spanned 2,700 msec. The 900-msec local pattern corresponded to the intermediate absolute temporal scale, and the 2,700-msec global pattern corresponded to the slow absolute temporal scale in the IS stimulus set.

\section{Procedure}

Each participant was assigned two target patterns: either risingrising and rising-falling or falling-falling and falling-rising. The two remaining patterns served as distractor patterns. The target patterns were combined with the irrelevant distractor patterns, such that if a target pattern was presented at the local level, a distractor pattern was presented at the global level (or vice versa). For every hierarchical stimulus presented, the participants identified which one of their two target patterns was presented, regardless of its level (a two-alternative forced choice). Note that all of the participants were presented with the entire stimulus set shown in Figure 1B, and the participants' target assignment determined which pattern was the target or distractor.

Each target pattern had an associated button. The participants responded using the index finger of either the left or the right hand on 
each trial and were encouraged to identify, as quickly and as accurately as possible, which of their two target patterns was presented. The participants were evenly assigned to one of four responsemapping groups (left: rising-rising, right: rising-falling; left: risingfalling, right: rising-rising; left: falling-rising, right: falling-falling; or left: falling-falling, right: falling-rising).

Each trial began with a white central visual fixation circle presented on a black background. This served as an alerting signal to the participants that the trial had begun. One 2,700-msec hierarchical auditory stimulus (the nine-tone sequence) was presented after $1,000 \mathrm{msec}$ of fixation. Each trial ended with the participants' responses or once $2,600 \mathrm{msec}$ elapsed if no response occurred. The silent intertrial intervals lasted $1,500 \mathrm{msec}$. The auditory stimuli were presented binaurally through Sennheiser HD 280 PRO headphones at $\sim 70 \mathrm{~dB}$ SPL.

The participants were presented with four orientation trials: each target alone at each temporal scale. They practiced their response mapping through 16 randomized target-alone presentations. ${ }^{1}$ After being informed that their targets would be combined with distractors, they were presented with four hierarchical stimuli. They were then given up to four 16-trial practice blocks ( $M=2.0$ blocks) to reach at least 14 correct. Four 65 -trial experimental blocks followed, separated by brief breaks. Each block had a fixed trial order to ensure balanced transitions between trials (see the Design section below), but block order was counterbalanced across participants.

\section{Design}

The full factorial design for Experiment 1 was target pattern $\times$ distractor pattern $\times$ target level $\times$ target priming $\times$ distractor priming $\times$ level priming. The first three variables related to within-trials manipulations (see the Trial types section below), whereas the last three variables related to between-trials manipulations (see the Priming section below).

Trial types. One nine-tone hierarchical stimulus was presented in isolation in each trial and can be described by target pattern (same/changing direction) $\times$ distractor pattern (same/changing direction) $\times$ target level (local/global). Same-direction patterns were rising-rising or falling-falling, and changing-direction patterns were rising-falling or falling-rising. This design notably allows the same stimulus to contribute to different trial types for different participants. For example, performance on a trial presenting a local rising-rising pattern with a global falling-rising pattern would contribute to the local same-direction condition for one participant and to the global changing-direction condition for another participant.

Figure 2 illustrates a sequence of five trials, assuming a target pattern assignment of rising-rising and rising-falling. On each trial, the target pattern is indicated by a dashed circle: same direction (rising-rising) on trials $n+2$ and $n+4$ and changing direction (rising-falling) on trials $n, n+1$, and $n+3$. The distractor patterns were same direction (falling-falling) on trials $n, n+1, n+2$, and $n+4$ and changing direction (falling-rising) on trial $n+3$. The target patterns were presented at the local level on trials $n, n+2$, and $n+3$ and at the global level on trials $n+1$ and $n+4$. Note that although the second local pattern is circled on local target trials, the participants could identify the local target pattern during any or all of its three instantiations within a trial (just as a local visual target might be identified from any of its many instantiations; see Figure 1A).

Priming. When the trial types are presented in succession, three priming factors emerge: target priming (target pattern: repeated/ changed) ${ }^{2}$ distractor priming (distractor pattern: repeated/changed), and level priming (target level: repeated/changed). Each of the eight trial types was immediately preceded equally often by each of the eight trial types, resulting in 64 transitions. Because the first trial was not subject to priming, 65 trials were required for each block.

Figure 2 also illustrates four intertrial transitions. Target priming was categorized as repeated for trial $n+1$ and changed for trials $n+2, n+3$, and $n+4$. Distractor priming was categorized as repeated for trials $n+1$ and $n+2$ and as changed for trials $n+3$ and $n+4$. Level priming was categorized as repeated for trial $n+3$ and as changed for trials $n+1, n+2$, and $n+4$.

\section{Analysis}

The hypotheses of Experiment 1 depended critically on only three of the manipulated factors: level, target priming, and level priming. Therefore, the analyses conducted were restricted to these variables and collapsed over all others. Each participant was presented with 32 observations from each of the eight relevant cells.

In addition to repeated measures ANOVAs, specific attention was paid to the target priming and level priming conditions. Repeatedversus changed-level paired comparisons were carried out separately for repeated and changed targets. Such analyses reveal whether apparent level-priming effects are being driven only by target repeti-

\section{Experiment 1}

Trial $n$

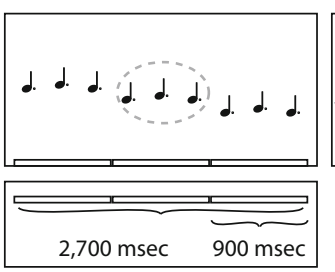

Target Pattern: $\quad$ R-F Distractor Pattern: $\quad F-F$ Target Level: Local

Target Priming: Distractor Priming: Level Priming:
Trial $n+1$
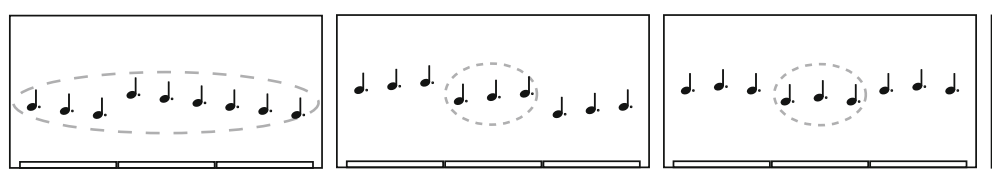

Trial $n+3$

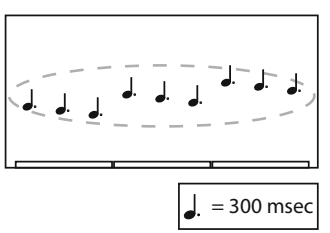

R-R

F-F

Global
$\mathrm{R}-\mathrm{R}$

F-F

Local

R-F
F-R
Local

Changed

Repeated

Changed
Changed

Changed

Repeated

Figure 2. Five trials are shown. Within each trial, one hierarchical stimulus (a sequence of nine 300-msec tones) was presented. One local three-tone pattern was presented three times sequentially to create the global pattern. Assuming a target assignment of risingfalling (R-F) and rising-rising (R-R) patterns, the dotted lines identify the target on each trial. The target pattern, distractor pattern, target level, target priming, distractor priming, and level priming variables are identified for each trial. The distractor patterns were either falling-falling $(\mathbf{F}-\mathbf{F})$ or falling-rising $(\mathbf{F}-\mathbf{R})$. 
tion. If a repeated-level advantage is only found for repeated targets, this is instead referred to as repetition priming. True level priming is supported when a repeated-level advantage is found for both repeated and changed targets.

Within-subjects effect sizes are reported as partial eta squared $\left(\eta_{\mathrm{p}}^{2}\right)$ for the ANOVAs and as Cohen's $d$ for $t$ tests, calculated as $\eta_{\mathrm{p}}^{2}=$ sum of squares effect $/($ sum of squares effect + sum of squares error $)$ and $d=$ difference score $/ \mathrm{SD}_{\text {difference score }}$.

\section{Results}

Mean errors and response times (RTs) relative to stimulus onset were analyzed. For the RT analyses, errors $(M=$ $3.7 \%$, range $=0.8 \%-10.9 \%$ ) or trials without a response $(M=0.05 \%)$ and all trials immediately following those trials $(M=3.5 \%)$ were excluded. For each block, the first trial was discarded because it was not subject to priming. Furthermore, only those RTs within $3 S D$ of each participant's mean RT were included ( $M=4.9 \%$ exclusion). Analyses with $p s>.10$ are not reported, except for main effects and planned comparisons (conducted with twotailed $t$ tests). The direction of RT and error effects was the same, unless indicated otherwise.

A repeated measures ANOVA with level (local/global), level priming (repeated/changed), and target priming (repeated/changed) as factors was performed. Main effects of level $\left[F(1,15)=15.7, p=.001, \eta_{\mathrm{p}}^{2}=.51\right.$; errors, $F<1]$ and level priming $\left[F(1,15)=53.2, p<.001, \eta_{\mathrm{p}}^{2}=\right.$ .78 ; errors, $\left.F(1,15)=5.4, p<.05, \eta_{\mathrm{p}}^{2}=.26\right]$ were present. The targets were responded to more quickly at the local than at the global level (by $405 \mathrm{msec}$ ), and repeatedlevel targets were responded to faster and more accurately than changed-level targets (by $203 \mathrm{msec}$ and 1.4\%). Target priming revealed a trend for changed-target responses to be slowed relative to repeated-target responses (by $55 \mathrm{msec}$ ) $\left[F(1,15)=3.0, p=.10, \eta_{\mathrm{p}}^{2}=.17\right.$; errors, $\left.F<1\right]$.

All higher order interactions were reliable for RTs (Figure 3$)$. The $2 \times 2$ interactions are described first, with the relevant paired comparisons. The interaction between level and level priming $\left[F(1,15)=8.1, p<.05, \eta_{\mathrm{p}}^{2}=.35\right]$ revealed that level priming was greater for local targets (293 msec) $[t(15)=5.6, p<.001, d=1.40]$ than for global targets $(109 \mathrm{msec})[t(15)=3.7, p<.005, d=$ 0.92]. The interaction between level and target priming $\left[F(1,15)=5.9, p<.05, \eta_{\mathrm{p}}^{2}=.28\right]$ showed that local targets benefited from target repetition relative to change $(121 \mathrm{msec})[t(15)=2.5, p<.05, d=0.62]$, whereas global targets were unaffected by target repetition or change $(|t|<1)$. The interaction between level priming and target priming $\left[F(1,15)=11.0, p=.005, \eta_{\mathrm{p}}^{2}=.42\right]$ revealed that level priming was greater for repeated targets $(273 \mathrm{msec})[t(15)=7.6, p<.001, d=1.88]$ than for changed targets $(136 \mathrm{msec})[t(15)=4.4, p=.001$, $d=1.11]$.

The three-way interaction was reliable $[F(1,15)=5.4$, $\left.p<.05, \eta_{\mathrm{p}}^{2}=.26\right]$. Two follow-up ANOVAs were conducted; for each level, a level priming $\times$ target priming analysis was performed. For local (intermediate) targets, level priming was greater for repeated than for changed targets $\left[F(1,15)=14.2, p<.01, \eta_{\mathrm{p}}^{2}=.49\right]$. The paired comparisons for local targets revealed that repeatedtarget level priming was $404 \mathrm{msec}[t(15)=5.8, p<$ $.001, d=1.44]$; for changed-target level priming, it was $184 \operatorname{msec}[t(15)=3.8, p<.005, d=0.95]$. However, for global (slow) targets, level priming was similar regardless of whether the target repeated or changed $(F<1)$.

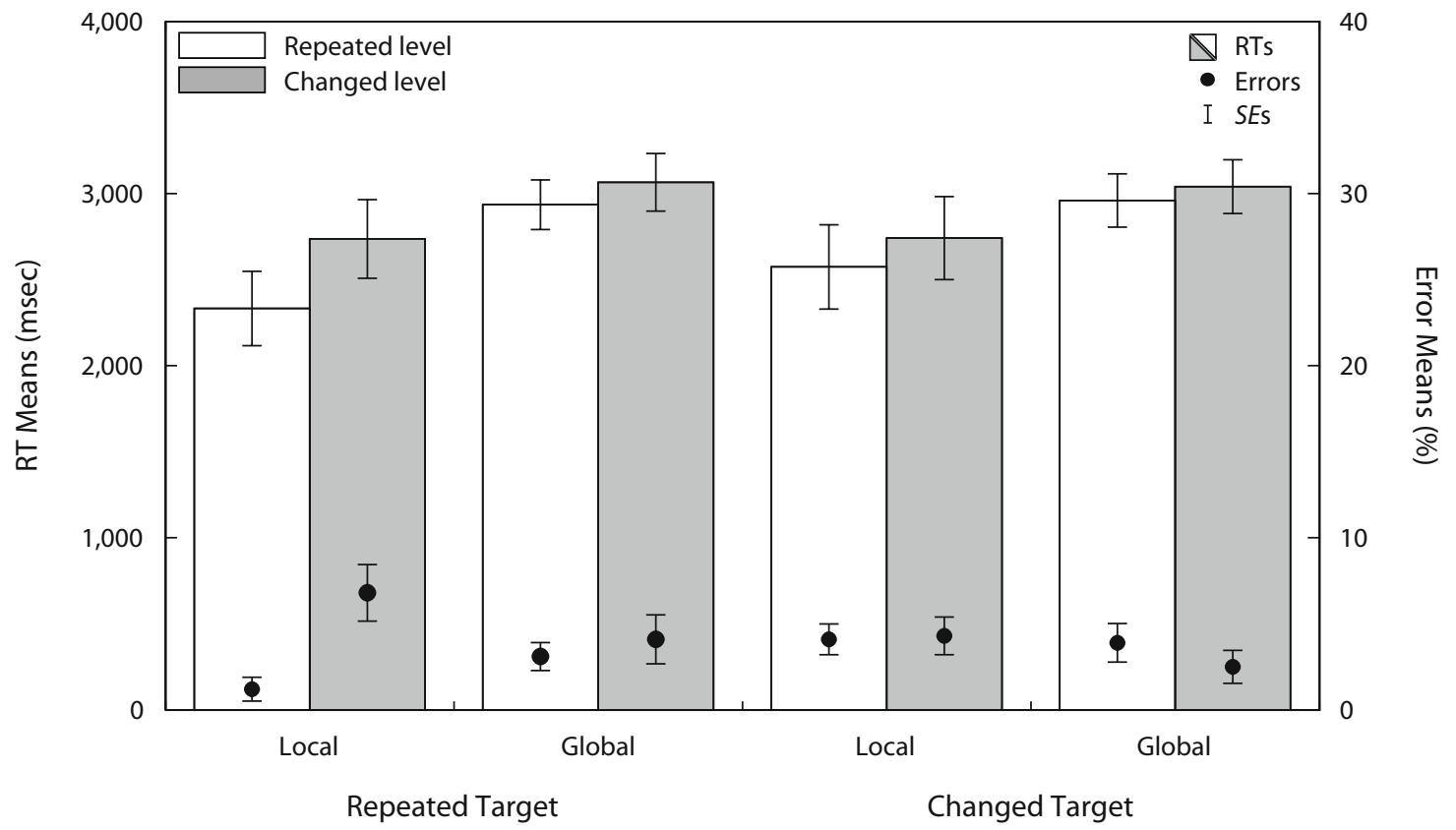

Figure 3. Experiment 1 results, in which the intermediate-slow stimulus set was used. Mean response times (RTs; bars) and error rates (points) are shown for the factors target priming, level, and level priming; error bars represent mean standard errors $(S E s)$. Level priming (repeated- < changed-level RTs) was present in all conditions. 
The paired comparisons for global targets revealed that repeated-target level priming was $130 \mathrm{msec}[t(15)=3.9$, $p=.001, d=0.98]$, and changed-target level priming was $92 \mathrm{msec}[t(15)=2.1, p=.054, d=0.52]$.

In summary, RT level priming was present, regardless of level (global or local) or target repetition (repeated or changed target) with the new stimulus set. Furthermore, local targets derived an additional RT advantage from target repetition.

In the error analyses, only two interactions reached significance: level $\times$ level priming $[F(1,15)=10.7, p=.005$, $\left.\eta_{\mathrm{p}}^{2}=.42\right]$ and level priming $\times$ target priming $[F(1,15)=$ $\left.9.7, p<.01, \eta_{\mathrm{p}}^{2}=.39\right]$. All other interactions revealed $F_{\mathrm{S}}<$ 1.2 (n.s.). Level priming was found only for targets at the local (intermediate) scale $(2.9 \%)[t(15)=3.5, p<.005$, $d=0.88$; global (slow) scale, $|t|<1]$ or for repeated targets $(3.3 \%)[t(15)=3.3, p=.005, d=0.80$; changed targets, $|t|<1]$. The pattern of errors was generally consistent with the RT data, although these data should be interpreted cautiously, because error rates were low $(M=3.7 \%)$.

\section{Discussion}

Using only the IS stimulus set, in which local patterns spanned $900 \mathrm{msec}$ and global patterns spanned 2,700 msec, true level priming (i.e., whether target patterns changed or repeated) was found for both the local and global levels. The results indicate that priming of temporal scales is not limited to the temporal scales of 300 and $900 \mathrm{msec}$ probed by the FI stimulus set, which was shown in Justus and List (2005). One difference was found between the FI and IS stimulus sets: With the IS stimulus set, RTs for global targets were slower than for local targets, whereas with the FI stimulus set, no RT difference was found for level. This is likely because, with the IS stimulus set, the participants could not differentiate between global target patterns until at least $1,800 \mathrm{msec}$ after stimulus onset, whereas with the FI stimulus set, they could do so after $600 \mathrm{msec}$. Despite the main effect of level in RTs, the participants still revealed RT advantages for repeated-level relative to changed-level conditions for both global and local targets.

Experiment 1 showed that temporal level priming generalizes to previously unexamined absolute temporal scales. Experiment 1 did not disambiguate the role of absolute and relative temporal information in level priming. Because local patterns always spanned $900 \mathrm{msec}$ and global patterns always spanned 2,700 msec, it remains undetermined whether level-priming was due to priming of the absolute temporal scale (i.e., 900 or $2,700 \mathrm{msec}$ ) or to the relative level (i.e., local or global, independent of absolute characteristics). Experiment 2 was therefore run to determine whether absolute or relative temporal information predominates in producing auditory level priming.

\section{EXPERIMENT 2}

To disentangle the contributions of absolute and relative temporal information in auditory level priming, we adopted the clever design of Kim, Ivry, and Robertson (1999), who addressed the question of whether visual level priming op- erates on the basis of absolute or relative size. To do so, they used two differently sized sets of visual local-global stimuli. The local form in the larger stimulus set spanned the same visual angle as the global form in the smaller stimulus set (Figure 4A). One hypothesis predicted that absolute size priming would occur (e.g., a global target from the small stimulus set would be facilitated when following an equally sized local target from the large stimulus set relative to when it followed a global target from the large stimulus set). Another hypothesis predicted that relative size priming would occur (e.g., a global target from the small stimulus set would be facilitated when following a global target from the large stimulus set relative to when it followed an equally sized local target from the large stimulus set). Kim et al. found evidence for both hypotheses. Target size repetition and level repetition reduced RTs. The novel result was that there was visual level priming, regardless of whether the absolute size repeated. Despite overall absolute size changes, the participants benefited from responding to sequential targets at similar levels of structure, demonstrating that visual level priming can operate relatively. Their findings illustrate a form of size invariance in the perception of visual hierarchical objects.

Similarly, we adopted the use of two auditory stimulus sets (IS and FI) in which local and global levels spanned different absolute temporal scales. Depending on the stimulus set, local patterns spanned either 300 or $900 \mathrm{msec}$, and global patterns spanned either 900 or $2,700 \mathrm{msec}$; the stimuli from the IS stimulus set were three times slower than the stimuli from the FI stimulus set (Figure 4B). We could thereby test whether temporal level priming persisted within each stimulus set in the context of interleaved stimulus sets and whether temporal level priming extended across the stimulus sets to reveal relative or absolute temporal priming. For the latter question, two predictions are as follows. First, if absolute properties of the stimuli underlie priming of temporal scales, targets should be facilitated when presented over the same absolute temporal scale as the target in the previous trial when the stimulus set changes. For instance (as is shown in trials $n$ and $n+1$, Figure 4B), identification of a global $900-\mathrm{msec}$ target pattern from the FI stimulus set should be facilitated following a local 900-msec target from the IS stimulus set. Second, if relative properties of the stimuli underlie priming of temporal scales, level repetition should be facilitated when the stimulus set changes. For instance (as is shown in trials $n+2$ and $n+3$, Figure 4B), a local 900-msec target pattern from the IS stimulus set should be facilitated following a local 300msec target from the FI stimulus set. By design, responses to changed-set targets at the intermediate temporal scale (900-msec patterns) have the potential to differentiate between these two possibilities.

\section{Method}

All methodological details were the same as those in Experiment 1 unless otherwise indicated.

\section{Participants}

Sixteen University of California, Berkeley, research participation pool volunteers provided informed consent and were awarded course 
A

Visual Relative Level-Priming Design

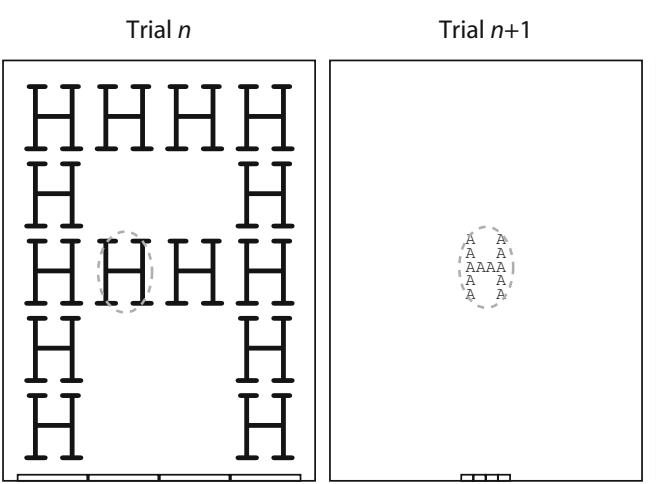

Trial $n+2$

Trial $n+3$

Trial $n+4$
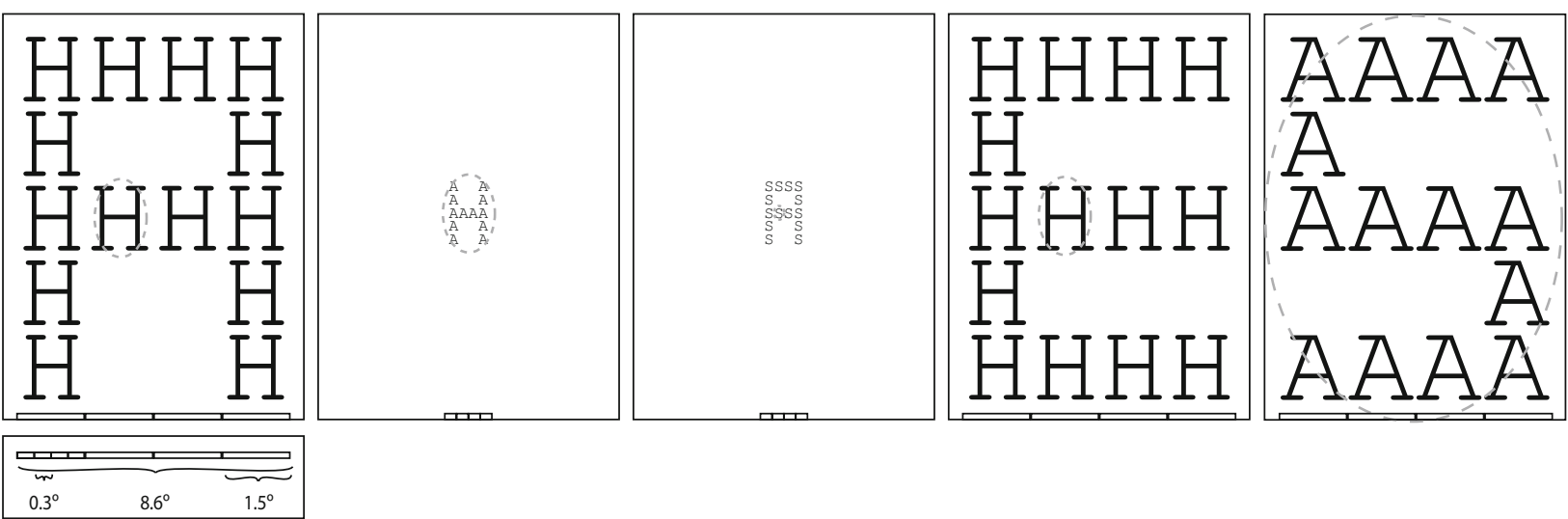

$\begin{array}{lc}\text { Target Pattern: } & \mathrm{H} \\ \text { Distractor Pattern: } & \mathrm{A} \\ \text { Target Level: } & \text { Local } \\ \text { Set: } & \mathrm{ML}\end{array}$

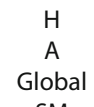

SM

$\begin{array}{ll}\text { Repeated } & \text { Changed } \\ \text { Repeated } & \text { Repeated } \\ \text { Changed } & \text { Changed }\end{array}$

S
A
Local
SM
Changed
Repeated
Changed
Repeated

$\mathrm{H}$
$\mathrm{E}$
Local
$\mathrm{ML}$

Changed

Changed

Repeated

Changed

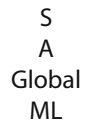

Changed

Changed

Changed

Repeated

B

Experiment 2: Auditory Relative Level-Priming Design

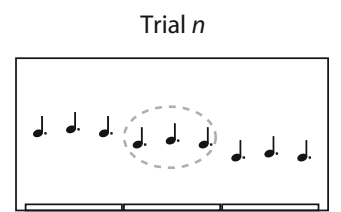

Trial $n+1$

Trial $n+2$

Trial $n+3$

Trial $n+4$
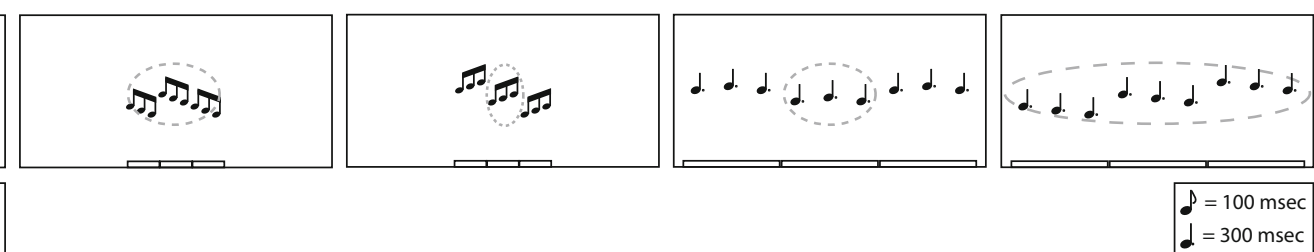

$300 \mathrm{msec} 2,700 \mathrm{msec} \overbrace{900 \mathrm{msec}}$

$\begin{array}{lc}\text { Target Pattern: } & \text { R-F } \\ \text { Distractor Pattern: } & \text { F-F } \\ \text { Target Level: } & \text { Local } \\ \text { Set: } & \text { IS }\end{array}$

$$
\begin{gathered}
\text { R-F } \\
\text { F-F } \\
\text { Global }
\end{gathered}
$$

$\mathrm{FI}$

Repeated
Repeated
Changed
Changed
R-R
$\mathrm{F}-\mathrm{F}$
Local

$\mathrm{FI}$

Changed

Repeated

Changed

Repeated
Target Priming:

Level Priming:

Set Priming:

Figure 4. Five trials are shown for testing relative level priming in the visual (A) and auditory (B) modalities. Three possible stimulus scales were used, although within each trial, the stimuli were presented over only two adjacent scales. In panel A, medium and large (ML) and small and medium (SM) scales are shown, based on Kim et al. (1999). In panel B, intermediate and slow (IS) and fast and intermediate (FI) scales are shown, as in Experiment 2. In panel A, target assignment was $H$ and $S$, and in panel $B$, target assignment was rising-falling $(R-F)$ and rising-rising $(R-R)$ patterns. In panel $A$, the visual distractor patterns were $A$ and $E$, and in panel $B$, the auditory distractor patterns were falling-falling $(\mathrm{F}-\mathrm{F})$ and falling-rising $(\mathrm{F}-\mathrm{R})$. The target pattern, distractor pattern, target level, set, target priming, distractor priming, level priming, and set priming variables are labelled for each trial.

credit for their participation. All reported right-handedness, normal hearing, and at least some musical experience (median $=10$ years, range $=3-25$ years). Their median age was 20 years (range $=$ $18-55$ years).

\section{Stimuli}

Two sets of stimuli were interleaved. The only difference between stimulus sets was the tone duration: $300 \mathrm{msec}$ in the IS stimulus set and $100 \mathrm{msec}$ in the FI stimulus set. Consequently, the nine-tone stimulus duration was either $2,700 \mathrm{msec}$ in the IS stimulus set or $900 \mathrm{msec}$ in the FI stimulus set. As in Experiment 1, stimuli from the IS stimulus set had local and global temporal scales unfolding over 900 and 2,700 msec, respectively. As in Justus and List (2005, Experiment 2), stimuli from the FI stimulus set ${ }^{3}$ had local and global temporal scales unfolding over 300 and $900 \mathrm{msec}$, respectively. Whether from the IS or FI stimulus set, the relatively slower 
of the two temporal scales (slow in IS and intermediate in FI) were deemed global, and the relatively faster of the two temporal scales (intermediate in IS and fast in FI) were deemed local. Note that the 900-msec patterns were local in the IS set, but global in the FI set. See Figure 4B for five illustrative trials. The auditory stimulus set manipulation is akin to the visual size manipulation Kim et al. (1999) used (compare Figure 4 A and B).

\section{Procedure}

The task and response mappings were the same as those in Experiment 1: The participants were assigned two target patterns to identify as quickly and as accurately as possible by pressing one of two buttons, regardless of their level (local or global). In Experiment 2 , there was an added requirement to make this identification regardless of the stimulus set.

Each trial began with $1,000 \mathrm{msec}$ of visual fixation before one hierarchical auditory stimulus was presented. If the stimulus was from the FI stimulus set, $900 \mathrm{msec}$ elapsed, whereas if the stimulus was from the IS stimulus set, 2,700 msec elapsed. Each trial ended with the participants' responses or once 2,600 msec elapsed if no response occurred. As before, 1,500-msec ITIs elapsed between trials. Auditory stimuli were presented binaurally through Sennheiser EH 2200 headphones at $70 \mathrm{~dB}$ SPL.

The participants were presented with six orientation trials: each target alone at each of the three absolute temporal scales $(300,900$, and $2,700 \mathrm{msec}$ ). They practiced their response mapping through 18 randomized target-alone presentations. ${ }^{4}$ After being informed that their targets would be combined with distractors, they were presented with six hierarchical stimuli. They were then given up to six 16-trial practice blocks $(M=2.9$ blocks $)$ to reach at least 14 trials correct. Four 65-trial experimental blocks followed, separated by brief breaks.

\section{Design}

The full factorial design was target pattern $\times$ distractor pattern $\times$ target level $\times$ set $\times$ target priming $\times$ distractor priming $\times$ level priming $\times$ set priming. The first four variables relate to within-trials manipulations (see the Trial types section below), whereas the last four variables relate to between-trials manipulations (see the Priming section below)

Trial types. The stimuli can be categorized into a four-factor trial type design (collapsing over counterbalanced target pattern assignments): target pattern (same/changing direction) $\times$ distractor pattern (same/changing direction) $\times$ target level (local $/$ global) $\times$ stimulus set (FI/IS).

Figure 4B also illustrates these factors, again assuming a target pattern assignment of rising-rising and rising-falling. Samedirection (rising-rising) target patterns are shown on trials $n+2$ and $n+4$, and changing-direction (rising-falling) target patterns are shown on trials $n, n+1$, and $n+3$. Same-direction (falling-falling) distractor patterns are shown on trials $n, n+1, n+2$, and $n+4$, and a changing-direction (falling-rising) distractor pattern is shown on trial $n+3$. The target patterns are shown at the local level on trials $n$, $n+2$, and $n+3$ and at the global level on trials $n+1$ and $n+4$. Trials $n, n+3$, and $n+4$ show stimuli from the IS stimulus set, whereas trials $n+1$ and $n+2$ show stimuli from the FI stimulus set.

Because of the set manipulation, each pattern could not be presented equally often at each of the three absolute temporal scales. A ratio of presentation for fast:intermediate:slow of 1:2:1 was adopted to equate the probabilities of local and global targets on each trial. ${ }^{5}$ In Figure 4B, targets are shown at the Fast scale on trial $n+2$; at the intermediate scale on trials $n, n+1$, and $n+3$; and at the slow scale on trial $n+4$. Note that the patterns were presented equiprobably at the local and global levels within the IS and FI stimulus sets.

Priming. When the trial types are presented in succession, four priming factors emerge: target priming (target pattern: repeated/ changed), distractor priming (distractor pattern: repeated/changed), level priming (target level: repeated/changed), and set priming (set: repeated/changed). Figure 4B also illustrates these four intertrial tran- sition variables. In trial $n+1$, the target pattern repeats, and in the remaining trials it changes. In trials $n+1$ and $n+2$, the distractor pattern repeats, and in the remaining trials it changes. In trial $n+3$, the target level repeats, and in the remaining trials it changes. The stimulus set repeats in trials $n+2$ and $n+4$ and changes in trials $n+1$ and $n+3$.

In this experiment, distractor and distractor priming were omitted from the within-blocks factorial combination (unlike in Experiment 1), because their inclusion would have required 257 trials/ block. However, the likelihood of each distractor pattern and whether the distractor was repeated or changed was equated within each 65-trial block.

\section{Analyses}

Two analyses were carried out to address our hypotheses. In the first analysis, we addressed the contributions of relative and absolute temporal information in level priming. To do so, we examined only the subset of trials in which the stimulus set changed between successive trials (i.e., IS to FI or FI to IS) and targets were presented at the intermediate scale (i.e., $900 \mathrm{msec}$ ). In the second set of analyses, we examined trials in which the stimulus set repeated between successive trials (i.e., IS to IS or FI to FI) to determine whether level priming persisted within sets, despite the interleaved context.

In the first analysis (see the Relative Versus Absolute Priming section below), the contributions of relative and absolute temporal information in level priming were addressed by examining the intermediate changed-set trials (Figure 5A). The intermediate target trials were matched across sets for both the proportion of presentation (recall the 1:2:1 fast:intermediate:slow target ratios) and their $900-\mathrm{msec}$ duration. As was previously discussed, by examining changed-set trials, we could probe absolute and relative influences. The critical analyses again involved the level priming and target priming conditions and the related paired comparisons. Each participant was presented with 16 observations per condition in this analysis. By design, a repeated absolute temporal scale (i.e., consecutive targets at $900 \mathrm{msec}$ ) corresponds to the changed-level condition, and a changed absolute temporal scale (i.e., a 900-msec target following a 300 - or 2,700-msec target) corresponds to the repeated-level condition. Therefore, faster repeated-level RTs than changed-level RTs would indicate a greater influence of relative versus absolute temporal priming. Conversely, faster changed-level RTs than repeated-level RTs would indicate a greater influence of absolute versus relative temporal priming. Furthermore, whether relative or absolute temporal priming occurs, it should occur for both repeated and changed targets.

Figure 5A presents a schematic depiction of the conditions and their constituent trials entered into the first analysis. Specifically, the analysis examined the following trials: intermediate-temporalscale targets presented either in the IS stimulus set, following a fasttemporal-scale target from the FI stimulus set (i.e., was local in both cases), or in the FI stimulus set, following a slow-temporal-scale target from the IS stimulus set (i.e., was global in both cases; Figure 5A, bottom row). These are the repeated-level (changed-absolute) trials, and they were compared with the changed-level (repeated-absolute) trials. The latter trials comprised intermediate-temporal-scale targets presented either over $900 \mathrm{msec}$ in the IS stimulus set, following a 900-msec intermediate-temporal-scale target from the FI stimulus set, or over $900 \mathrm{msec}$ in the FI stimulus set, following a $900-\mathrm{msec}$ intermediate-temporal-scale target from the IS stimulus set (Figure 5A, top row).

In addition, a second set of analyses was carried out on repeated-set trials to determine whether temporal level priming persisted within the IS and FI stimulus sets in the interleaved context (see the Repeated-Set Level Priming section below). For each stimulus set, a level priming $X$ target priming ANOVA was performed on repeated-set trials to evaluate level priming for both changed and repeated targets. If present, level priming would converge with previous experiments' results in which the stimulus set was uniform within a session. Each participant was presented with 16 observations per cell in these analyses. 
A

Repeated Target

\begin{tabular}{|c|c|c|c|}
\hline \multirow{6}{*}{ 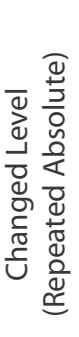 } & Scale & Trial $n-1$ & Trial $n$ \\
\hline & Slow & & $\mathrm{D}$ \\
\hline & Intermediate & $\mathrm{T}_{2}$ & $\mathrm{~T}_{2}$ \\
\hline & Fast & D & \\
\hline & Slow & $\mathrm{D}$ & \\
\hline & Intermediate & $T_{2}$ & $T_{2}$ \\
\hline & Fast & & D \\
\hline
\end{tabular}

Scale

Trial $n-1$

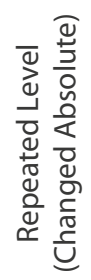

\begin{tabular}{lcc}
\hline & & \\
\hline Slow & & $\mathrm{D}$ \\
\hline Intermediate & $\mathrm{D}$ & $\mathrm{T}_{2}$ \\
\hline Fast & $\mathrm{T}_{2}$ & \\
\hline \hline Slow & $\mathrm{T}_{2}$ & \\
\hline Intermediate & $\mathrm{D}$ & $\mathrm{T}_{2}$ \\
\hline Fast & & $\mathrm{D}$ \\
\hline
\end{tabular}

Changed Target

Scale $\quad$ Trial $n-1$

Trial $n$

\begin{tabular}{lcc}
\hline Slow & & $\mathrm{D}$ \\
\hline Intermediate & $\mathrm{T}_{1}$ & $\mathrm{~T}_{2}$ \\
\hline Fast & $\mathrm{D}$ & \\
\hline & & \\
\hline Slow & $\mathrm{D}$ & \\
\hline Intermediate & $\mathrm{T}_{1}$ & $\mathrm{~T}_{2}$ \\
\hline Fast & & $\mathrm{D}$
\end{tabular}

Scale

Trial $n-1$

Trial $n$

\begin{tabular}{lcc}
\hline Slow & & $\mathrm{D}$ \\
\hline Intermediate & $\mathrm{D}$ & $\mathrm{T}_{2}$ \\
\hline Fast & $\mathrm{T}_{1}$ & \\
\hline & & \\
\hline Slow & $\mathrm{T}_{1}$ & \\
\hline Intermediate & $\mathrm{D}$ & $\mathrm{T}_{2}$ \\
\hline Fast & & $\mathrm{D}$ \\
\hline
\end{tabular}

$\mathrm{T}_{1}=$ Target Pattern 1

$\mathrm{T}_{2}=$ Target Pattern 2

$\mathrm{D}=$ Distractor pattern

B

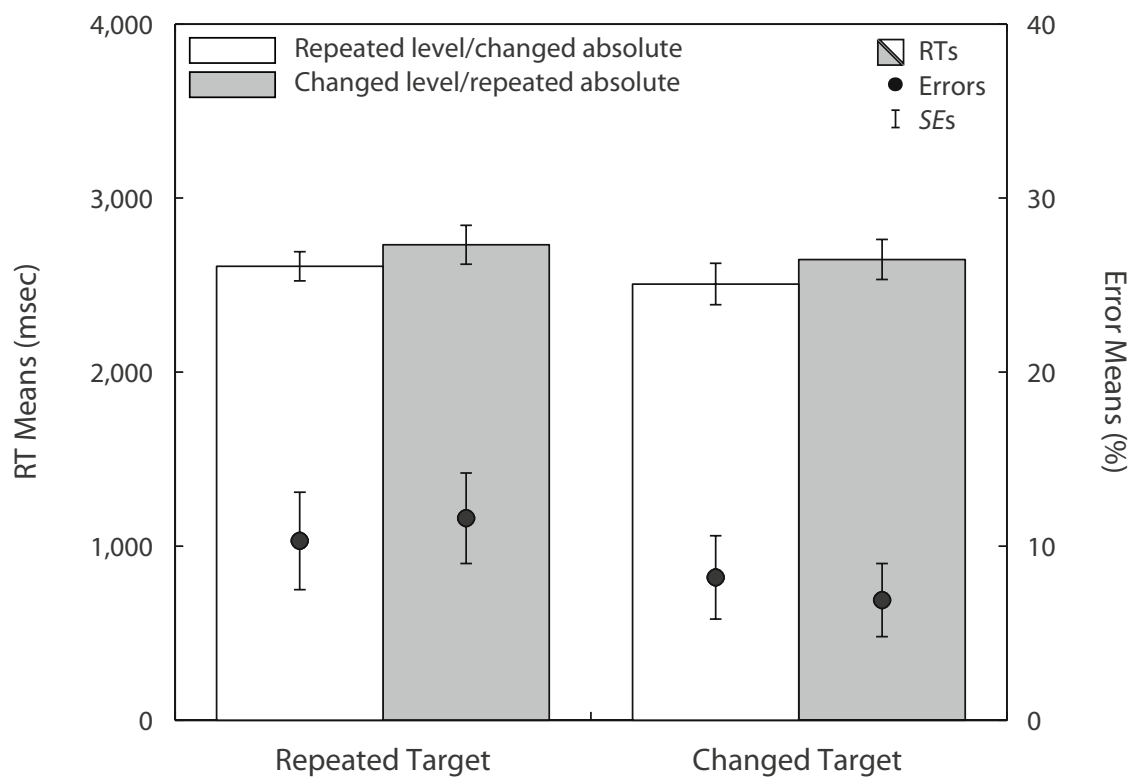

Figure 5. Intermediate (900-msec) changed-set trials from Experiment 2. In panel A, the trials contributing to the intermediate changed-set analyses are depicted schematically. Target (T) patterns and distractor (D) patterns are shown for the relevant trial transitions. Because each participant was assigned two target patterns, these are denoted as $T_{1}$ and $T_{2}$. In panel $B$, the results from the intermediate changed-set trials are shown for absolute versus relative level priming. Mean response times (RTs; bars) and error rates (points) are shown for the factors target priming and level priming; error bars represent mean standard errors (SEs). 


\section{Results}

Mean errors and RTs relative to stimulus onset were analyzed. For RT analyses, errors $(M=7.6 \%$, range $=$ $0.0 \%-18.1 \%)$ or trials without a response $(M=0.2 \%)$ and all trials immediately following those trials $(M=6.8 \%)$ were excluded. For each block, the first trial was discarded because it was not subject to priming. Furthermore, only those RTs within 3 SDs of each participant's mean RT for that stimulus set were included $\left(M_{\mathrm{FI} \text { set }}=0.5 \%, M_{\mathrm{IS} \text { set }}=\right.$ $2.2 \%$ exclusion). Analyses with $p \mathrm{~s}>.10$ are not reported, except for main effects and planned comparisons (conducted with two-tailed $t$ tests). The direction of RT and error effects was the same unless indicated otherwise.

\section{Relative Versus Absolute Priming}

To determine whether absolute or relative temporal priming was present, we analyzed only intermediate changedset trials. The trials in which targets were presented over the intermediate temporal scale and when the stimulus set changed were submitted to a level priming $\times$ target priming ANOVA, as well as level priming paired comparisons for repeated and changed targets (Figure 5B).

Both main effects were reliable: Repeated-level RTs were $133 \mathrm{msec}$ faster than changed-level RTs $[F(1,15)=$ $12.7, p<.01, \eta_{\mathrm{p}}^{2}=.46$; errors, $F<1$ ], and performance was better for changed targets than for repeated targets [RTs were 93 msec faster, $F(1,15)=6.7, p<.05, \eta_{\mathrm{p}}^{2}=$ .31 ; errors were fewer by $3.4 \%, F(1,15)=3.8, p=.07$, $\left.\eta_{\mathrm{p}}^{2}=.20\right]$. No interaction was present $(F<1)$ : Level priming was present regardless of target repetition [for repeated targets, $124 \mathrm{msec}, t(15)=2.7, p<.05, d=0.68$; errors, $|t|<1$; and for changed targets, $141 \mathrm{msec}, t(15)=$ 2.6, $p<.05, d=0.66$; errors, n.s. $]$.

Critically, the level priming found in the intermediate changed-set trials revealed that repeated level, not repeated absolute temporal scale, speeded RTs. (Recall the correspondence between the repeated-level and changedabsolute-scale conditions and between the changedlevel and repeated-absolute-scale conditions.) Because a repeated-level benefit was present whether or not the targets repeated, evidence for true relative temporal priming was found.

\section{Repeated-Set Level Priming}

To determine whether level priming for repeated temporal scales persisted in the context of interleaved stimulus sets, level priming was evaluated within stimulus sets (i.e., only for repeated-set trials). For the FI and IS stimulus sets, separate repeated measures ANOVAs were conducted for target priming $\times$ level $\times$ level priming $($ Figure 6), as in Experiment 1.

FI-set level priming. In the FI stimulus set (previously used in, e.g., Justus \& List, 2005), a main effect of level priming occurred (repeated $<$ changed: $93 \mathrm{msec}$ ) $\left[F(1,15)=11.6, p<.005, \eta_{\mathrm{p}}^{2}=.44\right.$; errors, $F(1,15)=$ $\left.6.3, p<.05, \eta_{\mathrm{p}}^{2}=.30\right]$. A trend for a main effect of level was present in RTs (global < local: $104 \mathrm{msec})[F(1,15)=$ $\left.3.3, p=.09, \eta_{\mathrm{p}}^{2}=.18\right]$ and reached significance in errors $($ global < local: $8.1 \%)\left[F(1,15)=4.5, p=.05, \eta_{\mathrm{p}}^{2}=.23\right]$. See Figure 6A.
In the FI stimulus set, target priming interacted with level $\left[F(1,15)=5.6, p<.05, \eta_{\mathrm{p}}^{2}=.27\right]$ : Repeated target RTs did not vary by level $(|t|<1)$, whereas global changed-target RTs were faster than local changed-target RTs (by $171 \mathrm{msec}$ ) $[t(15)=3.4, p<.05, d=0.59]$. A trend for target priming to interact with level priming was also found in RTs $\left[F(1,15)=3.4, p=.09, \eta_{\mathrm{p}}^{2}=.18\right]$. When the target changed, no level priming was observed in RTs $(|t|<1)$, whereas when the target repeated, level repetition speeded RTs by $182 \mathrm{msec}[t(15)=2.8, p<.05$, $d=0.69]$. All other RT and error effects had $F \mathrm{~s}<1$.

IS-set level priming. For repeated IS stimulus set trials (as in Experiment 1), level priming was not reliable (in RTs, repeated < changed: $62 \mathrm{msec})[F(1,15)=2.9, p=$ $.11, \eta_{\mathrm{p}}^{2}=.16$; errors, $\left.F=1\right]$. A main effect of level was found (global < local: $65 \mathrm{msec})[F(1,15)=13.1, p<.01$, $\eta_{\mathrm{p}}^{2}=.47$; errors, $\left.F(1,15)=3.7, p=.08, \eta_{\mathrm{p}}^{2}=.20\right]$. The level effect is opposite that found in Experiment 1; here, performance was better for global than for local targets. See Figure 6B.

Target priming interacted with level priming only in the error analysis $\left[F(1,15)=7.3, p<.05, \eta_{\mathrm{p}}^{2}=.33\right]$. When the target changed, reversed level priming was present as a trend in errors (repeated $>$ changed: $2.8 \%)[t(15)=1.8, p=.10$, $d=0.44]$. However, when the target repeated, accuracy was equivalent across conditions $(|t|<1)$ (Figure 6B). The participants sacrificed accuracy when the target changed and the level repeated. To determine whether true level priming was present, we examined level priming for repeated and changed targets. Only a trend for repeated-target level priming was found (119 msec) $[t(15)=1.9, p=.07, d=0.49$; changed-target level priming: $|t|<1]$. No other RT or error effects reached the reporting criterion.

When the FI and IS stimulus sets were interleaved and the overall stimulus duration could vary trial to trial, the previously demonstrated true temporal level priming in both the FI and IS stimulus sets was eliminated. Level priming was observed for neither stimulus set. For the FI stimulus set, repetition priming (level priming only for repeated targets) was observed for repeated-set transitions (Figure 6A). For the IS stimulus set, only weak repetition priming was observed. In Experiment 1 and in previous experiments (e.g., Justus \& List, 2005, Experiment 2), when either stimulus set was presented in isolation, both benefited from level repetition, whether targets repeated or changed. This divergence in results is likely due to the new context (i.e., the interleaved presentation of multiple stimulus sets) and only weakly revealed repetition priming for repeated-set transitions.

\section{Discussion}

In Experiment 2, we used auditory hierarchical stimuli in a priming design. Unlike previous studies in which one stimulus set was employed, by introducing two sets of stimuli that varied in absolute time, we pitted the contributions of absolute and relative temporal information against each other.

Responses to 900-msec intermediate targets from changed-set trials (i.e., FI followed by IS or IS followed by FI) revealed that relative level priming occurred: Re- 
A

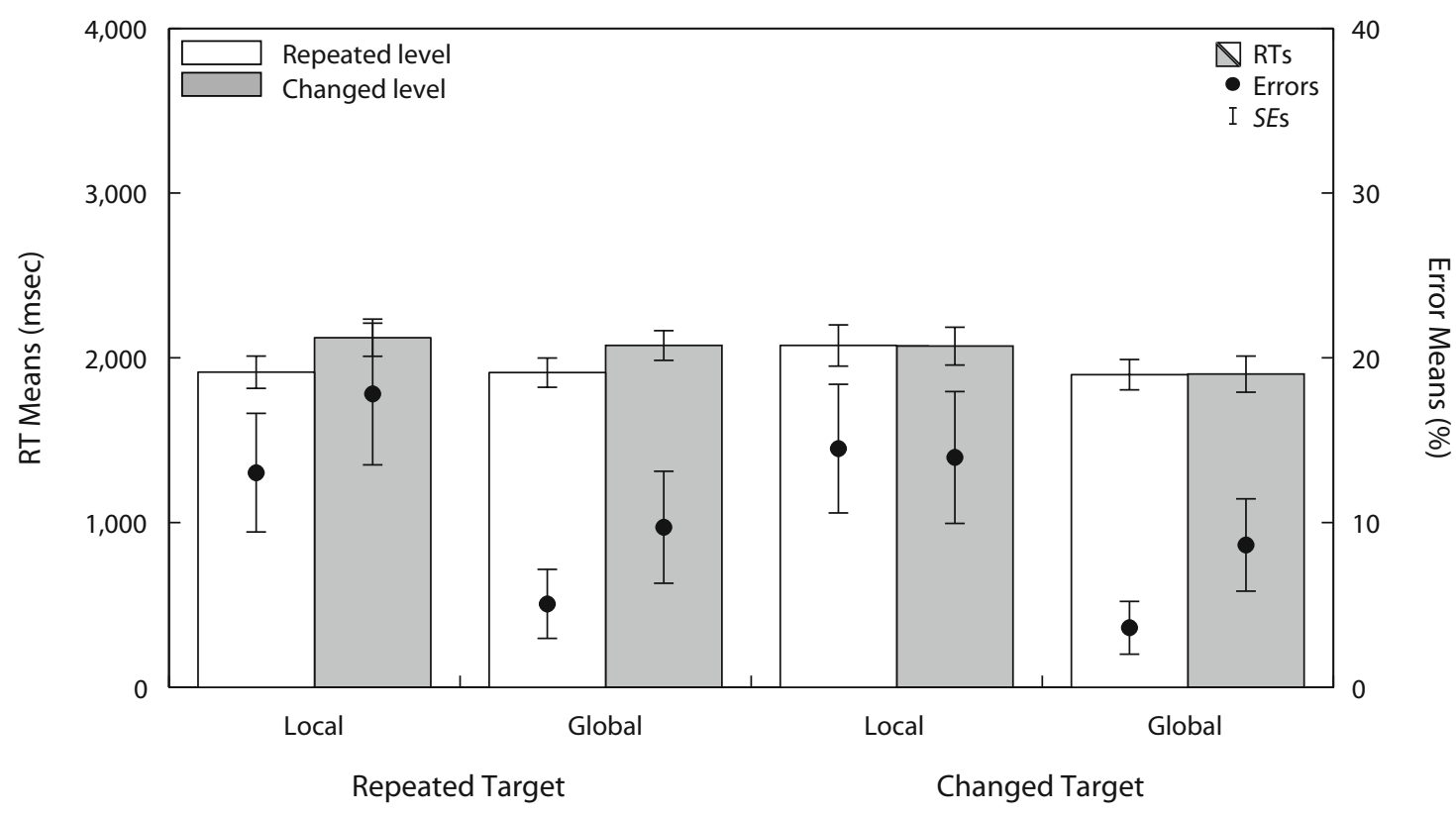

B

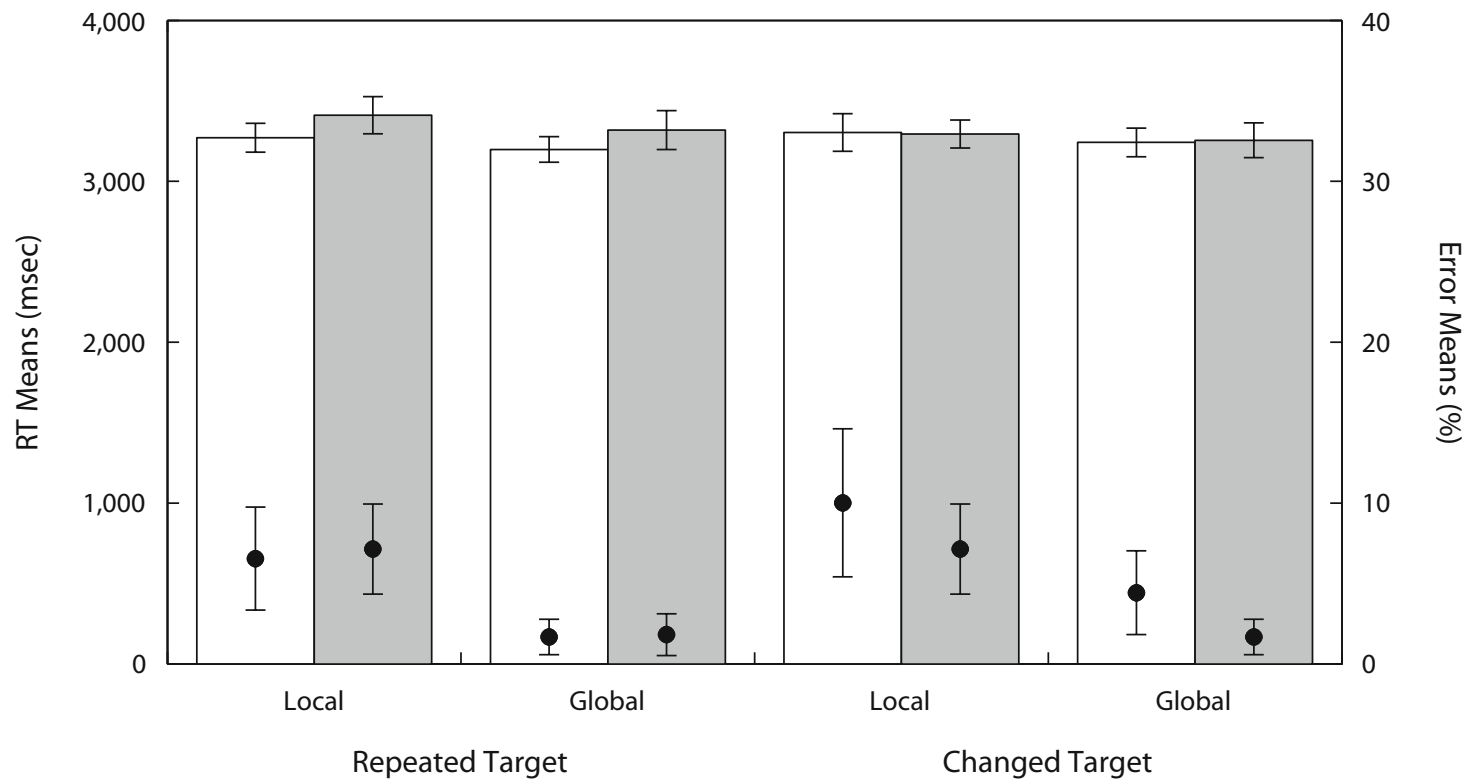

Figure 6. Experiment 2 results from repeated-set trials for the fast-intermediate (FI) stimulus set (A) and intermediateslow (IS) stimulus set (B). For each set, mean response times (RTs; bars) and error rates (points) are shown for the factors target priming, level, and level priming; error bars represent mean standard errors (SEs).

sponding to a repeated level facilitated performance for repeated and changed targets, even though absolute temporal parameters changed. If absolute priming had occurred instead, responses would have been facilitated for changed-level targets (i.e., with the same absolute timing: both $900 \mathrm{msec}$ ) relative to repeated-level targets (i.e., with different absolute timing: $900 \mathrm{msec}$ preceded by 2,700 or $300 \mathrm{msec}$ ). Because we found an advantage for repeated level and because relative and absolute priming were pitted against one another in these conditions, we conclude that relative level priming was greater in magnitude than any absolute priming. Therefore, the observed level priming was predominantly carried by relative temporal information in changed-set contexts.

As was previously noted, the design of Experiment 2 was based on that used by Kim et al. (1999). A direct 
comparison between their visual and our auditory results cannot be made, because identical analyses were not conducted. ${ }^{6}$ However, the RT means from their intermediate changed-set trials from their Experiments 1A, 1B, and 2, although collapsed over the target priming factor, do indicate that relative level repetition was speeded compared with relative level change. Their visual results are consistent with the auditory results that we report here: Both findings support the presence of relative level priming. Such scale-invariant priming may enable continuous object selection or expectancy generation in changing environments in both modalities.

We also examined whether intertrial temporal level priming persisted for repeated-set trials (i.e., FI followed by FI or IS followed by IS) when we interleaved the FI and IS stimulus sets. Surprisingly, true level priming (for both repeated and changed targets) was eliminated within each stimulus set. Only repetition-priming (i.e., level priming for repeated targets) persisted within the interleaved context for repeated-stimulus-set trials, and only weakly so for the IS set. Note that level priming for repeated and changed targets has been shown in each of these stimulus sets when presented in isolation (for the IS stimulus set in Experiment 1 and for the FI stimulus set in Experiment 2 of Justus \& List, 2005). The lack of true level priming only occurred in the context of interleaved stimulus sets. In summary, Experiment 2 revealed that in the presence of duration-varying events, relative information guides selection when event durations change, whereas absolute (pattern and duration) information guides selection when event durations repeat.

\section{GENERAL DISCUSSION}

Given the central role of time in auditory perception, it is important to understand how directing attention to various scales of this dimension affects subsequent processing. In the present experiments, we have made use of a priming measure that establishes that attending and responding to patterns emerging over a given temporal scale will facilitate processing of subsequent patterns over that same temporal scale as compared with those presented over a different temporal scale. We have here shown that our previous findings were not limited to patterns extending over 300 or $900 \mathrm{msec}$; level priming also extends to patterns emerging over 2,700 msec. Although we have only tested it under laboratory conditions, this priming mechanism might generally assist perceivers in anticipating and rapidly responding to future events that are related to (i.e., emerging over the same temporal scales as) present relevant events.

Furthermore, we have addressed whether temporal level priming occurs on the basis of perceivers attending to the absolute or to the relative temporal characteristics of the hierarchical stimuli. In other words, was previously found temporal level priming due to attending to the $300-\mathrm{msec}$ pattern after a 300 -msec target? Or was priming due to attending to the relatively fast pattern after a relatively fast target? To disentangle these questions, we presented interleaved stimulus sets spanning either $900 \mathrm{msec}(3 \times 300$ msec patterns $)$ or $2,700 \mathrm{msec}(3 \times 900$-msec patterns $)$.
When stimulus set changed, there was only evidence for relative temporal level priming: For IS (local/900 msec and global/2,700 $\mathrm{msec}$ ) followed by FI (local/300 msec and global/900 msec) targets, or vice versa, performance was best for relatively fast targets after relatively fast targets or for relatively slow targets after relatively slow targets. However, when stimulus set repeated, only repetition priming was present (facilitation for repeated target pattern and repeated temporal scale). This highlights flexibility in the perceptual system: When confronted with a changing environment, perceivers make use of relative information to guide subsequent selection.

\section{Hierarchically Structured Stimuli}

As was previously noted, the use of hierarchical stimuli in studies of temporal level priming enables the researcher to examine the effects of selective attention. Significant auditory events in everyday life, such as speech and music, have highly complex spectrotemporal profiles. Although the hierarchical stimuli that we used were not equivalently complex, they did contain multiple levels of information. Hierarchical stimuli have the benefit of challenging the perceiver to select relevant information, as is often necessary in real-world environments. In addition, by using hierarchical stimuli and examining how attention is allocated from one trial to the next, we have revealed that expectancies are created on the basis of the stimulus structure. Performance enhancements for discrimination, memory, and production of structured auditory sequences that have been previously reported (e.g., Boltz, 1998; Johnston \& Jones, 2006; Jones, Boltz, \& Kidd, 1982; C. Palmer \& Krumhansl, 1990; Povel, 1981; Sturges \& Martin, 1974) may benefit in part from the type of expectancy generation found here.

\section{Relational Invariance}

The present findings are relevant to the broadly studied topic of relational invariance. Relational invariance describes a situation in which properties of a representation (e.g., object, event, or sequence) can be uniformly altered without disrupting the representation's identity. For instance, in vision, an object might be translated or rotated in space, yet it retains its shape and identity. Any viable theory of visual object recognition must account for invariance (see S. E. Palmer, 1999, for a discussion). In motor control, relational invariance has been studied inamong other areas-locomotion, typing, and handwriting. Researchers have asked whether people walk, type, and write consistently, regardless of the speed or scale of the movements. Here, the answer remains controversial; researchers have argued for both sides of the issue (e.g., Fraisse, 1946; Gentner, 1982, 1987; Viviani \& Terzuolo, 1980).

In audition, as in vision, demonstrations of relational invariance have been less contentious. For instance, researchers have shown preservation of melodic phrase recognition despite frequency transpositions (e.g., Attneave \& Olson, 1971; Bartlett \& Dowling, 1980; Cuddy \& Cohen, 1976; Dowling \& Fujitani, 1971; Halpern, Bartlett, \& Dowling, 1995). As was discussed in the intro- 
duction, other studies have revealed melodic invariance over tempo changes (e.g., Andrews et al., 1998; Halpern, 1988; Warren et al., 1991). Pattern stability over varying frequencies or time has also been demonstrated in infants (e.g., Morrongiello, 1984; Trainor \& Trehub, 1992). Generalization of patterns over varied frequencies has even been shown to occur without awareness, as has been shown in electrophysiological mismatch negativity studies (e.g., Paavilainen, Jaramillo, Näätänen, \& Winkler, 1999; van Zuijen, Sussman, Winkler, Näätänen, \& Tervaniemi, 2004, 2005). Presumably, this ability to extract consistent stimulus patterns, while disregarding other stimulus changes, enables object recognition under varied environmental conditions (for more on auditory objects, see Griffiths \& Warren, 2004).

In the present experiments, we contribute to this body of evidence in the area of relational invariance for pitch pattern recognition over temporal manipulations. One form of evidence was from Experiment 1 and previous studies (Justus \& List, 2005; List \& Justus, 2007): Participants were able to recognize the patterns assigned to them whether presented in the local or global form. This demonstrates their ability to abstract relative pitch relationships (contours) over differing temporal and absolute pitch scales from the hierarchical stimuli. Experiment 1 extended our previous findings by revealing that these same patterns were recognizable to participants over an absolute temporal scale different from what had previously been tested: $2,700 \mathrm{msec}$. The ability to extract an abstract pattern at either the local or global level from hierarchically structured stimuli is evidence for relative capabilities within a single event and complements the previous tempo and pitch invariance studies described above. The second form of evidence from the present study is the demonstration of relative influences between successive events through our priming results. In Experiment 2, when absolute temporal information changed, performance was modulated by relative temporal information: Temporal level priming occurred, despite changes in the absolute temporal dimensions of the stimuli. This is an important addition to research on relational invariance: Relative temporal information is used not only in identifying a given event, but it can also affect subsequent processing.

One final point bears mentioning. We do not argue that perceivers are unaware of the absolute variations in the stimuli, but rather argue that the pattern is recognized in various forms. Our investigations were designed to explore whether absolute or relative information underlies temporal level priming when the task requires perceivers to discriminate patterns regardless of their absolute temporal parameters. Under these conditions, unless repetition priming occurred, we found compelling evidence in favor of relative temporal biases beyond any absolute temporal influences. Other researchers, however, have demonstrated the use of stable absolute auditory representations (e.g., Honing, 2006; Levitin, 1994; Levitin \& Cook, 1996). Although potentially contradictory, the relative and absolute accounts are easily reconciled when the types of experimental designs or stimuli used are examined. In studies in which pitch and tempo invariance are explored, partici- pants are required to identify sequences, or changes in sequences, despite manipulations in pitch or tempo. Notably, participants are necessarily exposed to stimuli varying in those dimensions. In studies in which absolute capabilities are explored, researchers typically use stimuli that tend to have a unique pitch and temporal instantiation (as in pop melodies) or use a task that critically depends on the use of absolute information. It is therefore not surprising that evidence for both relative and absolute capabilities exists. The various results do, however, underscore the great flexibility available to us: We adjust on the basis of current environmental demands, whether absolute or relative.

\section{AUTHOR NOTE}

A.L. is now at the Department of Psychology, Northwestern University. At the University of Wales, Bangor, we thank Becca Henderson and Steve Tipper for their support in maintaining the Community Research Panel (Wellcome Programme Grant WT071924), through which some participants in Experiment 1 were recruited. A.L. received support from postdoctoral NRSA Fellowship F32 NS55531. At the University of California, Berkeley, we thank Lia Ernst for her assistance in collecting the data from Experiment 2. The data from Experiment 2 have been previously reported in A.L.'s 2006 doctoral dissertation, Investigating Auditory Local-Global Processing Using Visual Research As a Model, University of California, Berkeley. Correspondence concerning this article should be addressed to A. List, Department of Psychology, Northwestern University, 2029 Sheridan Road, Evanston, Illinois 60208-2710 (e-mail: a-list@northwestern.edu).

\section{REFERENCES}

Andrews, M. W., Dowling, W. J., Bartlett, J. C., \& Halpern, A. R. (1998). Identification of speeded and slowed familiar melodies by younger, middle-aged, and older musicians and nonmusicians. Psychology \& Aging, 13, 462-471. doi:10.1037/0882-7974.13.3.462

Attneave, F., \& Olson, R. K. (1971). Pitch as a medium: A new approach to psychophysical scaling. American Journal of Psychology, 84, 147-166. doi: $10.2307 / 1421351$

BARNES, R., \& Jones, M. R. (2000). Expectancy, attention, and time. Cognitive Psychology, 41, 254-311. doi:10.1006/cogp.2000.0738

Bartlett, J. C., \& Dowling, W. J. (1980). Recognition of transposed melodies: A key-distance effect in developmental perspective. Journal of Experimental Psychology: Human Perception \& Performance, 6, 501-515. doi:10.1037/0096-1523.6.3.501

Bharucha, J. J., \& Stoeckig, K. (1986). Reaction time and musical expectancy: Priming of chords. Journal of Experimental Psychology: Human Perception \& Performance, 12, 403-410. doi:10.1037/0096 $-1523.12 .4 .403$

Bharucha, J. J., \& Stoeckig, K. (1987). Priming of chords: Spreading activation or overlapping frequency spectra? Perception \& Psychophysics, 41, 519-524.

Bigand, E., \& Pineau, M. (1997). Global context effects on musical expectancy. Perception \& Psychophysics, 59, 1098-1107.

Bigand, E., Poulin, B., Tillmann, B., Madurell, F., \& D’Adamo, D. A. (2003). Sensory versus cognitive components in harmonic priming. Journal of Experimental Psychology: Human Perception \& Performance, 29, 159-171. doi:10.1037/0096-1523.29.1.159

BoLTZ, M. G. (1998). The processing of temporal and nontemporal information in the remembering of event durations and musical structure. Journal of Experimental Psychology: Human Perception \& Performance, 24, 1087-1104. doi:10.1037/0096-1523.24.4.1087

Crum, P. A., \& Hafter, E. R. (2008). Predicting the path of a changing sound: Velocity tracking and auditory continuity. Journal of the Acoustical Society of America, 124, 1116-1129. doi:10.1121/1.2945117

Cuddy, L. L., \& Cohen, A. J. (1976). Recognition of transposed melodic sequences. Quarterly Journal of Experimental Psychology, 28, 255-270.

Deutsch, D. (1986). Recognition of durations embedded in temporal patterns. Perception \& Psychophysics, 39, 179-186.

Dowling, W. J., Bartlett, J. C., Halpern, A. R., \& Andrews, W. M. 
(2008). Melody recognition at fast and slow tempos: Effects of age, experience, and familiarity. Perception \& Psychophysics, 70, 496-502. doi:10.3758/PP.70.3.496

Dowling, W. J., \& FuJiTani, D. S. (1971). Contour, interval, and pitch recognition in memory for melodies. Journal of the Acoustical Society of America, 49(Suppl. 2), 524-531. doi:10.1121/1.1912382

Dowling, W. J., Lung, K. M., \& Herrbold, S. (1987). Aiming attention in pitch and time in the perception of interleaved melodies. Perception \& Psychophysics, 41, 642-656.

DraKe, C., \& BotTe, M. C. (1993). Tempo sensitivity in auditory sequences: Evidence for a multiple-look model. Perception \& Psychophysics, 54, 277-286.

Drake, C., Jones, M. R., \& Baruch, C. (2000). The development of rhythmic attending in auditory sequences: Attunement, referent period, focal attending. Cognition, 77, 251-288. doi:10.1016/S0010 -0277(00)00106-2

Dyson, B. J., \& Alain, C. (2008). Is a change as good with a rest? Task-dependent effects of intertrial contingency on concurrent sound segregation. Brain Research, 1189, 135-144. doi:10.1016/ j.brainres.2007.10.093

Fraisse, P. (1946). Contribution à l'étude du rhythme en tant que forme temporelle. Journal de Psychologie Normale et Pathologique, 39, 283-304.

Fraisse, P. (1963). The psychology of time. New York: Harper.

Fraisse, P. (1982). Rhythm and tempo. In D. Deutsch (Ed.), The Psychology of music (pp. 149-180). New York: Academic Press.

GentNER, D. R. (1982). Evidence against a central control model of timing in typing. Journal of Experimental Psychology: Human Perception \& Performance, 8, 793-810. doi:10.1037/0096-1523.8 .6 .793

Gentner, D. R. (1987). Timing of skilled motor performance: Tests of the proportional duration model. Psychological Review, 94, 255276. doi:10.1037/0033-295X.94.2.255

Green, T. J., \& McKeown, J. D. (2001). Capture of attention in selective frequency listening. Journal of Experimental Psychology: Human Perception \& Performance, 27, 1197-1210. doi:10.1037/0096-1523.27 5.1197

GrifFITHS, T. D., \& WARREN, J. D. (2004). What is an auditory object? Nature Reviews Neuroscience, 5, 887-892. doi:10.1038/nrn1538

HalPern, A. R. (1988). Perceived and imagined tempos of familiar songs. Music Perception, 6, 193-202.

Halpern, A. R., Bartlett, J. C., \& Dowling, W. J. (1995). Aging and experience in the recognition of musical transpositions. Psychology \& Aging, 10, 325-342. doi:10.1037/0882-7974.10.3.325

HaNDEL, S. (1993). The effect of tempo and tone duration on rhythm discrimination. Perception \& Psychophysics, 54, 370-382.

HoNING, H. (2006). Evidence for tempo-specific timing in music using a Web-based experimental setup. Journal of Experimental Psychology: Human Perception \& Performance, 32, 780-786. doi:10.1037/0096 $-1523.32 .3 .780$

Horváth, J., Czigler, I., Sussman, E., \& Winkler, I. (2001). Simultaneously active pre-attentive representations of local and global rules for sound sequences in the human brain. Cognitive Brain Research, 12, 131-144. doi:10.1016/S0926-6410(01)00038-6

Johnston, H. M., \& Jones, M. R. (2006). Higher order pattern structure influences auditory representational momentum. Journal of Experimental Psychology: Human Perception \& Performance, 32, 2-17. doi:10.1037/0096-1523.32.1.2

JoNES, M. R. (1976). Time, our lost dimension: Toward a new theory of perception, attention, and memory. Psychological Review, 83, 323-355. doi:10.1037/0033-295X.83.5.323

Jones, M. R., \& Boltz, M. (1989). Dynamic attending and responses to time. Psychological Review, 96, 459-491. doi:10.1037/0033-295X.96 .3 .459

Jones, M. R., Boltz, M., \& KidD, G. (1982). Controlled attending as a function of melodic and temporal context. Perception \& Psychophysics, 32, 211-218.

Jones, M. R., Johnston, H. M., \& Puente, J. (2006). Effects of auditory pattern structure on anticipatory and reactive attending. Cognitive Psychology, 53, 59-96. doi:10.1016/j.cogpsych.2006.01.003

Jones, M. R., \& McAuley, J. D. (2005). Time judgments in global temporal contexts. Perception \& Psychophysics, 67, 398-417.
Jones, M. R., Moynihan, H., MacKenzie, N., \& Puente, J. (2002). Temporal aspects of stimulus-driven attending in dynamic arrays. Psychological Science, 13, 313-319. doi:10.1111/1467-9280.00458

Justus, T., \& List, A. (2005). Auditory attention to frequency and time: An analogy to visual local-global stimuli. Cognition, 98, 3151. doi:10.1016/j.cognition.2004.11.001

Kidd, G., Boltz, M., \& Jones, M. R. (1984). Some effects of rhythmic context on melody recognition. American Journal of Psychology, 97, 153-173.

Kim, N., Ivry, R. B., \& Robertson, L. C. (1999). Sequential priming in hierarchically organized figures: Effects of target level and target resolution. Journal of Experimental Psychology: Human Perception \& Performance, 25, 715-729. doi:10.1037/0096-1523.25.3.715

LARGE, E. W., \& Jones, M. R. (1999). The dynamics of attending: How people track time-varying events. Psychological Review, 106, 119159. doi:10.1037/0033-295X.106.1.119

Levitin, D. J. (1994). Absolute memory for musical pitch: Evidence from the production of learned melodies. Perception \& Psychophysics, 56, 414-423.

Levitin, D. J., \& Coок, P. R. (1996). Memory for musical tempo: Additional evidence that auditory memory is absolute. Perception \& Psychophysics, 58, 927-935.

Lewkowicz, D. J., \& Marcovitch, S. (2006). Perception of audiovisual rhythm and its invariance in 4- to 10-month-old infants. Developmental Psychobiology, 48, 288-300. doi:10.1002/dev.20140

LIsT, A., \& Justus, T. (2007). Auditory priming of frequency and temporal information: Effects of lateralized presentation. Laterality, 12, 507-535. doi:10.1080/13576500701566727

List, A., Justus, T., Robertson, L. C., \& Bentin, S. (2007). A mismatch negativity study of local-global auditory processing. Brain Research, 1153, 122-133. doi:10.1016/j.brainres.2007.03.040

Marmel, F., Tillmann, B., \& Dowling, W. J. (2008). Tonal expectations influence pitch perception. Perception \& Psychophysics, 70, 841-852. doi:10.3758/PP.70.5.841

McAuley, J. D., \& Miller, N. S. (2007). Picking up the pace: Effects of global temporal context on sensitivity to the tempo of auditory sequences. Perception \& Psychophysics, 69, 709-718.

Morrongiello, B. A. (1984). Auditory temporal pattern perception in 6- and 12-month-old infants. Developmental Psychology, 20, 441448. doi:10.1037/0012-1649.20.3.441

Navon, D. (1977). Forest before trees: The precedence of global features in visual perception. Cognitive Psychology, 9, 353-383. doi:10.1016/0010-0285(77)90012-3

Paavilainen, P., Jaramillo, M., Nä̈̈tänen, R., \& Winkler, I. (1999). Neuronal populations in the human brain extracting invariant relationships from acoustic variance. Neuroscience Letters, $\mathbf{2 6 5}$, 179-182. doi:10.1016/S0304-3940(99)00237-2

Palmer, C., \& Krumhansl, C. L. (1990). Mental representations for musical meter. Journal of Experimental Psychology: Human Perception \& Performance, 16, 728-741. doi:10.1037/0096-1523.16.4.728

Palmer, S. E. (1999). Vision science: Photons to phenomenology. Cambridge, MA: MIT Press.

Peretz, I. (1990). Processing of local and global musical information by unilateral brain-damaged patients. Brain, 113, 1185-1205. doi:10.1093/brain/113.4.1185

Povel, D. J. (1981). Internal representation of simple temporal patterns. Journal of Experimental Psychology: Human Perception \& Performance, 7, 3-18. doi:10.1037/0096-1523.7.1.3

Repr, B. H. (2002). Perception of timing is more context sensitive than sensorimotor synchronization. Perception \& Psychophysics, 64, 703-716.

Robertson, L. C. (1996). Attentional persistence for features of hierarchical patterns. Journal of Experimental Psychology: General, 125, 227-249. doi:10.1037/0096-3445.125.3.227

Schiavetto, A., Cortese, F., \& Alain, C. (1999). Global and local processing of musical sequences: An event-related brain potential study. NeuroReport, 10, 2467-2472. doi:10.1097/00001756-199908200 $-00006$

Schmuckler, M. A., \& Boltz, M. G. (1994). Harmonic and rhythmic influences on musical expectancy. Perception \& Psychophysics, 56, 313-325.

Sturges, P. T., \& Martin, J. G. (1974). Rhythmic structure in audi- 
tory temporal pattern perception and immediate memory. Journal of Experimental Psychology, 102, 377-383. doi:10.1037/h0035866

Tekman, H. G., \& Bharucha, J. J. (1998). Implicit knowledge versus psychoacoustic similarity in priming of chords. Journal of Experimental Psychology: Human Perception \& Performance, 24, 252-260. doi:10.1037/0096-1523.24.1.252

Tillmann, B., Bigand, E., \& Pineau, M. (1998). Effects of global and local contexts on harmonic expectancy. Music Perception, 16, 99-117.

Tillmann, B., \& Lebrun-Guillaud, G. (2006). Influence of tonal and temporal expectations on chord processing and on completion judgments of chord sequences. Psychological Research, 70, 345-358. doi:10.1007/s00426-005-0222-0

TIPPER, S. P. (1985). The negative priming effect: Inhibitory priming with to be ignored objects. Quarterly Journal of Experimental Psychology, 37A, 571-590.

Trainor, L. J., \& Trehub, S. E. (1992). A comparison of infants' and adults' sensitivity to western musical structure. Journal of Experimental Psychology: Human Perception \& Performance, 18, 394-402. doi:10.1037/0096-1523.18.2.394

van ZuiJen, T. L., Sussman, E., Winkler, I., NäÄtÄnen, R., \& TerVANIEMI, M. (2004). Grouping of sequential sounds - an event-related potential study comparing musicians and nonmusicians. Journal of Cognitive Neuroscience, 16, 331-338. doi:10.1162/089892904322984607

van Zuijen, T. L., Sussman, E., Winkler, I., NäÄtÄnen, R., \& TerVANIEMI, M. (2005). Auditory organization of sound sequences by a temporal or numerical regularity - a mismatch negativity study comparing musicians and nonmusicians. Cognitive Brain Research, 23, 270-276. doi:10.1016/j.cogbrainres.2004.10.007

Viviani, P., \& Terzuolo, C. (1980). Space-time invariance in learned motor skills. In G. E. Stelmach \& J. Requin (Eds.), Tutorials in motor behavior (pp. 525-533). Amsterdam: North-Holland.

WARD, L. M. (1982). Determinants of attention to local and global features of visual forms. Journal of Experimental Psychology: Human Perception \& Performance, 8, 562-581. doi:10.1037/0096-1523.8.4.562

WARD, L. M. (1997). Involuntary listening aids hearing. Psychological Science, 8, 112-118. doi:10.1111/j.1467-9280.1997.tb00692.x

Warren, R. M., Gardner, D. A., Brubaker, B. S., \& Bashford, J. A., JR. (1991). Melodic and nonmelodic sequences of tones: Effects of duration on perception. Music Perception, 8, 277-290.

Yee, W., Holleran, S., \& Jones, M. R. (1994). Sensitivity to event timing in regular and irregular sequences: Influences of musical skill. Perception \& Psychophysics, 56, 461-471.

\section{NOTES}

1. When presented alone (i.e., not in hierarchical form), the $900-\mathrm{msec}$ intermediate target patterns were composed of a sequence of three 100msec tones (10-msec ramps on and off), with 200-msec ISIs between tones. The 2,700-msec slow target patterns were composed of a sequence of three 300-msec tones (10-msec ramps on and off), with 600-msec ISIs. The four possible target patterns were created using the tones $\mathrm{F}_{3}$, $\mathrm{C}_{4}$, and $\mathrm{F}_{4}$.

2. Given that each target pattern was assigned to a response, the effects of target and target priming can be equally attributed to effects of response and response priming, respectively.

3. In previous studies (Justus \& List, 2005; List \& Justus, 2007; List et al., 2007), the slow temporal window spanned $900 \mathrm{msec}$, whereas in the present study, the $900-\mathrm{msec}$ temporal window corresponds to the intermediate temporal scale.

4. When presented alone (i.e., not in hierarchical form), the 300-msec fast target patterns were composed of a sequence of three 100 -msec tones (10-msec ramps on and off), without ISIs. The four possible target patterns were chosen from $\mathrm{C}_{4}, \mathrm{D}_{4}$, and $\mathrm{E}_{4}$ to form any of the four possible target patterns. The $900-\mathrm{msec}$ intermediate target patterns were composed of a sequence of three 100-msec tones (10-msec ramps on and off), with 200 -msec ISIs between tones. The tones were chosen from $\mathrm{F}_{3}, \mathrm{C}_{4}$, and $\mathrm{F}_{4}$ to form any of the four possible target patterns. The 2,700-msec slow target patterns were composed of a sequence of three 300-msec tones (10msec ramps on and off), with 600-msec ISIs. The tones were chosen from $\mathrm{F}_{3}, \mathrm{C}_{4}$, and $\mathrm{F}_{4}$ to form any of the four possible target patterns.

5. If, instead, an overall fast:intermediate:slow ratio of 1:1:1 had been adopted, on any given trial from the IS set, the local:global ratio would have been 2:1, and from the FI set, the local:global ratio would have been $1: 2$, which was undesirable.

6. Because they found no interactions with target priming, their results were collapsed over that factor. In the auditory studies, we examined this factor separately to dissociate repetition from level priming.

(Manuscript received March 2, 2008; revision accepted for publication September 2, 2009.) 